\title{
IMMUNOSTIMULATION OF TIGER SHRIMP (Penaeus monodon) HEMOCYTES FOR GENERATION OF MICROBICIDAL SUBSTANCES: ANALYSIS OF REACTIVE OXYGEN SPECIES
}

\author{
Yen-Ling Song* and Yeun-Ting Hsieh† \\ *Department of Zoology and †Institute of Fisheries Science, National Taiwan University, Taipei 106, \\ Taiwan, ROC
}

(Submitted December 1993; Accepted April 1994)

$\square$ Abstract - NBT staining was used to determine the presence of superoxide anions $\left(\mathrm{O}_{2}^{-}\right)$ produced by tiger shrimp (Penaeus monodon) hemocytes attached to a coverslip. When cells were treated with $\beta$-glucan, blue granules were observed in $41 \%$ of studied hemocyte cytoplasm. For zymosan-treated, PMA-treated, and control cells, the percentages of hemocytes showing similar blue granules were 31,9 , and $5 \%$, respectively. A comparison of stimulative effects on 15 hemocyte suspensions, each collected from a single tiger shrimp, showed that $\beta$-glucan had the strongest effect. on intracellular $\mathrm{O}_{2}^{-}$generation, followed by zymosan and PMA $\left(2.5,2\right.$, and 1.3 times greater than the $\mathrm{O}_{2}^{-}$ generated by the control group, respectively). After oxidizing phenol red to measure the amounts of hydrogen peroxide $\left(\mathrm{H}_{2} \mathrm{O}_{2}\right)$ produced by the hemocytes, we found that $\beta$-glucan had the strongest stimulative effect (12.2 nmol/mg protein), followed by zymosan and PMA (7.2 and $2.6 \mathrm{nmol} / \mathrm{mg}$, respectively). However, a luminol-enhanced chemiluminescence analysis of hypochlorites $\left(\mathrm{OCl}^{-}\right)$produced by the experimental hemocytes showed that neither zymosan nor $\beta$-glucan had a stimulative effect on $\mathrm{OCl}^{-}$production. However, following PMA stimulation, hemocyte chemiluminescence was detected although only at $\mathbf{1 . 7}$ $\mathrm{mV}$. Using $\mathrm{H}_{2} \mathrm{O}_{2}$ as substrate and guaiacol as an electron acceptor, the enzyme activity of crude enzyme extract derived from broken hemocytes was analyzed; enzyme activity sim-

Address correspondence to Dr. Yen-Ling Song. ilar to that of human myeloperoxidase (MPO) $(0.104 \mathrm{U} / \mathrm{mg}$ protein) was observed. The data showed that only PMA had any stimulative effect on MPO-like enzyme activity (2.23 times that of the control group); zymosan and $\beta$-glucan did not have any observable effects on this specific enzyme activity. This is the first documented demonstration of a respiratory burst in shrimp hemocytes.

$\square$ Keywords-Immunostimulant; $\beta$-glucan; PMA; Zymosan; Tiger shrimp (Penaeus monodon); Hemocytes; Reactive oxygen species.

\section{Introduction}

Polymorphonuclear leucocytes and monocytes have been proven to be the main hemocytes in vertebrate phagocytosis. When microorganisms are engulfed by these hemocytes, a series of microbicidal substances that either inhibit microbial activities or completely digest the microorganisms is generated. These substances include highly reactive oxygen species such as superoxide anions $\left(\mathrm{O}_{2}^{-}\right)$, hydrogen peroxide $\left(\mathrm{H}_{2} \mathrm{O}_{2}\right)$, hydroxide ions $\left(\mathrm{OH}^{-}\right)$, singlet oxygen $\left(\mathrm{O}_{2}^{1}\right)$, myeloperoxidase (MPO)-catalyzed hypochlorite, and digestive enzymes within cytoplasmic granules.

Numerous assays can be used to detect these highly reactive oxygen spe- 
cies. Nitroblue tetrazolium (NBT) staining has been used for both qualitative and quantitative analyses of $\mathrm{O}_{2}^{-}$generated by hemocytes, and the oxidation of phenol red has been used as an indicator for quantifying hemocyte-generated extracellular $\mathrm{H}_{2} \mathrm{O}_{2}$ (1); in addition, luminolenhanced chemiluminescence has been used to analyze $\mathrm{OCl}^{-}$(2). However, few investigators have studied the metabolic events associated with phagocytosis in shrimp or the activation of shrimp phagocytosis by foreign materials.

For the present study, the reactive oxygen species and MPO generated by tiger shrimp (Penaeus monodon) hemocytes were analyzed via the abovementioned methods. In addition, the effects of immunostimulants such as phorbol myristate acetate (PMA), zymosan, and $\beta$-glucan on the generation of reactive oxygen species by shrimp hemocytes were compared. Our results may lead to the creation of an effective strategy for enhancing disease resistance in cultured shrimp.

\section{Materials and Methods}

\section{Hemocytes}

Tiger shrimp (purchased from a local market) weighing 25-40 g were kept in a $120-\mathrm{L}$ fiber reenforced plastic container supplied with a constant flow of recirculating brackish water with $2.5 \%$ salinity and $25^{\circ} \mathrm{C}$ temperature. Approximately $1.5 \mathrm{~mL}$ of shrimp hemolymph was collected from the first abdominal segment of a single shrimp with a 26-gauge hypodermic needle on a $2-\mathrm{mL}$ syringe containing $0.5 \mathrm{~mL}$ of anticoagulant $(0.01 \mathrm{M}$ tris- $\mathrm{HCl}, 0.25 M$ sucrose, $0.1 M$ sodium citrate; $\mathrm{pH}$ 7.6). The collected hemolymph was centrifuged at $300 \times g$ for $10 \mathrm{~min}$ at $4^{\circ} \mathrm{C}$; the resultant hemocyte pellet was then resuspended to $10^{7}$ cells/
mL in a modified complete Hank's balanced salt solution minus phenol red (MCHBSS, Sigma).

\section{Immunostimulants}

We tested the following immunostimulants for the generation of various reactive oxygen species from shrimp hemocytes: (a) phorbol 12-myristate 13acetate (PMA, Sigma); (b) zymosan (a protein-carbohydrate complex extracted from the cell walls of Saccharomyces cerevisiae, Sigma); (c) $\beta$-glucan ( $\beta-1,3$, and $\beta-1,6$ linked polyglucose) extracted from $S$. cerevisiae (Biotec Mackzymal, Tromso).

PMA is a surface-active agent of respiratory burst response in fish (3). Its soluble nature increases the potential of achieving reproducible results from superoxide anion assays (4). Zymosan (used as a possible natural immunostimulant) is known to enhance nonspecific defenses in certain organisms via the activation of the properdin system. $\beta$-glucan (also used as a natural immunostimulant) has been shown to induce cellular defense responses in crustaceans $(5,6)$. Our preliminary research showed that the optimal $\mathrm{O}_{2}^{-}$stimulative concentrations of PMA, zymosan, and $\beta$-glucan were $250 \mathrm{ng} / \mathrm{mL}, 2.5 \mathrm{mg} / \mathrm{mL}$, and $2 \mathrm{mg} /$ $\mathrm{mL}$, respectively.

\section{Intracellular Superoxide Anion $\left(\mathrm{O}_{2}^{-}\right)$Detection}

Qualitative assay. Fifty microliters of shrimp hemolymph was placed on a coverslip. After $1 \mathrm{~h}$ of adhesion, nonadhesive cells were washed off with $\mathrm{MCH}$ BSS. The hemocyte-containing coverslip was then turned upside down onto a slide that had been previously coated with a mixture of $50 \mu \mathrm{L}$ NBT $(0.3 \%$ in $\mathrm{MCH}$ BSS) and an equal volume of one of the 
three immunostimulants. After $30 \mathrm{~min}$ at $37^{\circ} \mathrm{C}$, the NBT reduction reaction had taken place and individual hemocyte cytoplasms examined under a light microscope for blue granules of reduced formazan. We then calculated the percentage of hemocytes showing these cytoplasmic blue granules from 250 observed hemocytes. Hemocytes that reacted with the NBT/MCHBSS mixture (instead of the NBT/immunostimulant mixture) were used as control.

Quantitative assay. Each well of a 96well microtiter plate was coated with 100 $\mu \mathrm{L}$ of poly-L-lysine solution $(0.2 \%$, Sigma) to increase the number of adhesive hemocytes (7). One hundred microliters of hemocyte suspension collected from a single shrimp was added to each of the four wells and then cytocentrifuged (Kubota, KN-70) at $300 \times g$ for 10 min. After removing the supernatant, $100 \mu \mathrm{L}$ of each immunostimulant (PMA, zymosan, or $\beta$-glucan) was added and allowed to react for $30 \mathrm{~min}$ at $37^{\circ} \mathrm{C}$. MCHBSS was added to the remaining hemocyte suspension as a control. We then discarded the immunostimulant solution, washed the hemocytes three times with MCHBSS, then stained them with NBT solution $(0.3 \%, 100 \mu \mathrm{L})$ for 30 $\min$ at $37^{\circ} \mathrm{C}$. The staining reaction was terminated by removing the NBT solution and adding absolute methanol. After three washings with $70 \%$ methanol, the hemocytes were air-dried and coated with a solution of $\mathrm{KOH}(120 \mu \mathrm{L}, 2 M)$ and DMSO $(140 \mu \mathrm{L})$ to dissolve the cytoplasmic formazan; the optical densities of the dissolved cytoplasmic formazan at $630 \mathrm{~nm}\left(\mathrm{OD}_{630}\right)$ were then measured with a Precision microplate reader (Emax) $(8,9)$. In order to determine the reproducibility of our results, hemocytes collected from 15 shrimp were individually assayed. We used the ratio of $\mathrm{OD}_{630}$ from the stimulated hemocytes to the $\mathrm{OD}_{630}$ of control hemocytes as an index for com- paring the effects of different immunostimulants on the generation of $\mathrm{O}_{2}^{-}$.

\section{Extracellular Hydrogen Peroxide $\left(\mathrm{H}_{2} \mathrm{O}_{2}\right)$ Detection}

Genfa and Dasgupta (10) first described an assay of the peroxidasedependent oxidation of phenol red by $\mathrm{H}_{2} \mathrm{O}_{2}$. Following their procedures, we prepared a phenol red solution (PRS) containing $0.001 \%$ phenol red and $0.005 \%$ horseradish peroxidase just before use. Approximately $10^{7}$ hemocytes were placed onto a 24-well microtiter plate precoated with poly-L-lysine. The hemocytes were first washed three times with MCHBSS, then $1 \mathrm{~mL}$ of PRS and $0.5 \mathrm{~mL}$ of one of the three immunostimulants were added to each well to stimulate the respiratory burst. After being allowed to react for $1 \mathrm{~h}$ at $37^{\circ} \mathrm{C}$, optical densities were determined with a spectrophotometer (Hitachi 2000) at $610 \mathrm{~nm}$ using PRS plus MCHBSS as a blank.

We converted our readings to nanomoles of $\mathrm{H}_{2} \mathrm{O}_{2}$ by using a standard curve established from solutions with known $\mathrm{H}_{2} \mathrm{O}_{2}$ molarities $(2,4,6,8,10 \mu M)$. Protein concentrations of $\mathrm{NaOH}$-dissolving hemocytes present in each well were estimated with a Bradford reagent (BioRad); we then calculated the $\mathrm{H}_{2} \mathrm{O}_{2}$ (nmol) released per hemocyte protein (mg) for each well.

\section{Chemiluminescence (CL) Assay}

According to procedures described by Van Dyke et al. (2), $0.3 \mathrm{~mL}$ of luminol solution (0.1 $\mathrm{m} M$, Sigma) and an equal volume of hemocyte suspension $\left(5 \times 10^{7}\right.$ cells $/ \mathrm{mL}$ ) were mixed and maintained at $24^{\circ} \mathrm{C}$. This solution was then put into a glass tube $(8-\mathrm{mm}$ diameter $\times 50-\mathrm{mm}$ height) that was placed into a reaction chamber to measure background light. 
After establishing constant background counts, $0.3 \mathrm{ml}$ of each immunostimulant suspension was added to initiate CL; CL values were measured for $1 \mathrm{~h}$ at $1-\mathrm{min}$ intervals with a luminometer (Turner, KD-20e).

\section{MPO Activity Assay}

Crude MPO extraction. Our MPO extraction technique was a modification of the procedures described by Bakkenist et al. (11) and Pember et al. $(12,13)$. Hemocytes were suspended at $10^{7}$ cells/ $\mathrm{mL}$ in $0.34 M$ ice-cold sucrose containing $10 \mu \mathrm{g} / \mathrm{mL}$ each of phenylmethylsulfonylfluoride (PMSF) and L-1-tosylamide2-phenylethylchloromethyl ketone (TPCK) plus $1 \mathrm{~m} M$ EDTA. Homogenates were produced with a Teflon-glass homogenizer ( $4000 \mathrm{rpm}, 1 \mathrm{~min}$, Tline), then centrifuged at $500 \times g$ for $5 \mathrm{~min}$ at $4^{\circ} \mathrm{C}$. Supernatants were collected, and pellets containing unbroken hemocytes were rehomogenized and centrifuged, after which the supernatants were pooled; this process was repeated (usually 1-2 times) until MPO was essentially undetectable. The pooled supernatants were centrifuged at $27000 \times g$ for $15 \mathrm{~min}$ at $4^{\circ} \mathrm{C}$; supernatant containing MPO was dialyzed against $10 \mathrm{~m} M$ sodium phosphate buffer ( $\mathrm{pH} 7.0$ ), and the resultant precipitate was removed by centrifugation at $27000 \times g$ for $15 \mathrm{~min}$.

Assay. Four hundred microliters of each of the three immunostimulants was added to the hemocyte suspension $(600$ $\mu \mathrm{L})$ and allowed to react at $37^{\circ} \mathrm{C}$ for 40 min. An equal volume of MCHBSS added to a hemocyte suspension was used as a control. Crude MPO was extracted using the procedures described above, and enzyme activity was measured using methods described by Desser et al. (14). One unit of activity was defined as the amount of enzyme catalyzing the decomposition of $1 \mu \mathrm{mol}$
$\mathrm{H}_{2} \mathrm{O}_{2}$ in $1 \mathrm{~min}$ at $25^{\circ} \mathrm{C}$, with a $26.6 \mathrm{mM}^{-1}$ $\mathrm{cm}^{-1}$ coefficient for tetraguaiacol at 470 $\mathrm{nm}$. Protein concentrations of crude MPO were determined via a Bradford procedure, with bovine serum albumin used as a standard. Our preliminary investigations revealed the following optimal values for the measurement of MPO activity: substrate solution $\mathrm{pH}$ at 7.0 ; $\mathrm{H}_{2} \mathrm{O}_{2}$ concentration at $0.4 \mathrm{mM}$; and $\mathrm{NaCl}$ concentration at $2.0 \%$.

\section{Results}

We found that most of the shrimp hemocytes that adhered to our coverslips had both a low ratio of nucleus size to cytoplasm as well as a low number of small granules in their cytoplasm. We used NBT staining to determine the presence of $\mathrm{O}_{2}^{-}$anion produced by these hemocytes. In $\beta$-glucan-treated cells, blue granules were observed in the cytoplasm of $41 \%$ of the hemocytes (Fig. 1a). For zymosan-treated, PMA-treated, and control cells, the percentages of hemocytes with blue granules present were 31 , 9 , and 5\%, respectively (Figs. $1 \mathrm{~b}-\mathrm{d}$ ).

A quantitative analysis of the stimulative effects of the three immunostimulants on hemocytes revealed that $\beta$-glucan had the strongest effect, followed by zymosan and PMA $(2.5,2$, and 1.3 times stronger than that of the control group, respectively) (Table 1). After oxidizing phenol red to measure the amount of $\mathrm{H}_{2} \mathrm{O}_{2}$ produced by our observed hemocytes, we found that $\beta$-glucan had the strongest stimulative effect $(12.2 \mathrm{nmol} /$ mg protein), followed by zymosan and PMA ( 7.2 and $2.6 \mathrm{nmol} / \mathrm{mg}$, respectively) (Fig. 2). However, the amount of $\mathrm{H}_{2} \mathrm{O}_{2}$ produced by the stimulated hemocytes varied significantly among individual shrimp. Luminol-enhanced chemiluminescence analysis of the $\mathrm{OCl}^{-}$produced by our experimental hemocytes showed that zymosan and $\beta$-glucan had no stimulative effect on $\mathrm{OCl}^{-}$production; PMA 

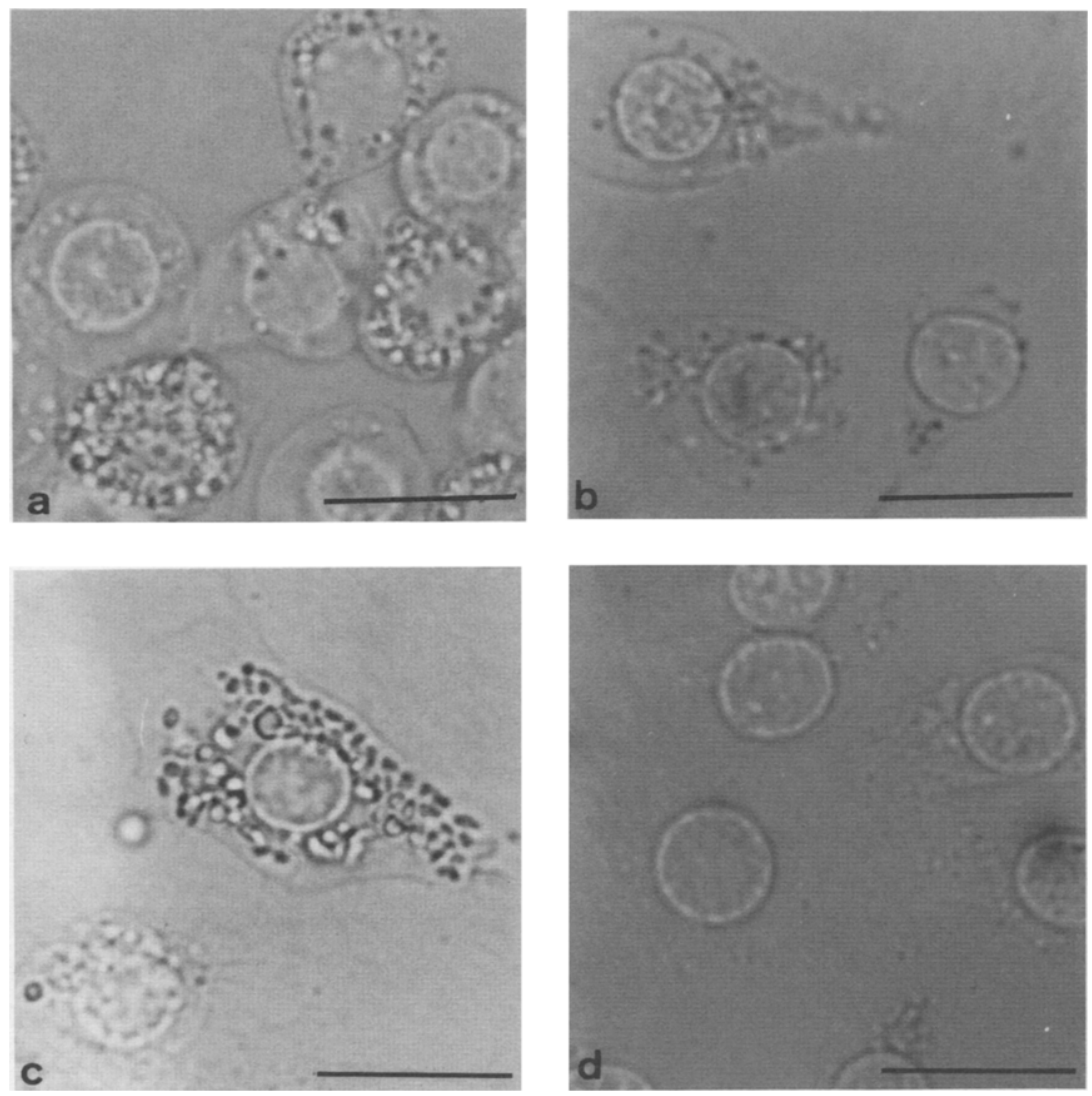

Figure 1. Shrimp hemocytes stained with nitroblue tetrazolium $(0.3 \%)$. Blue granules were observed in the cytoplasm of $41 \%$ of the hemocytes treated with (a) $\beta$-glucan $(2 \mathrm{mg} / \mathrm{mL})$. For (b) zymosan $(2.5 \mathrm{mg} / \mathrm{mL}$ ) treated, (c) phorbol myristate acetate $(250 \mathrm{ng} / \mathrm{mL}$ ) treated, and (d) MCHBSS treated cells, the percentages of hemocytes with blue granules present were 31,9 , and $5 \%$, respectively. $\times 2500$; bar $=10 \mu \mathrm{m}$.

stimulation enhanced hemocyte chemiluminescence, but only to a maximum of $1.7 \mathrm{mV}$ (Fig. 3).

Finally, using $\mathrm{H}_{2} \mathrm{O}_{2}$ as substrate and guaiacol as an electron acceptor, we analyzed the enzyme activity of crude ex- tract derived from broken hemocytes, and found enzyme activity similar to that of human MPO $(0.104 \mathrm{U} / \mathrm{mg}$ protein). Our data showed that only PMA had any stimulative effect on MPO-like enzyme activity (2.23 times that of the control

Table 1. Effects of Immunostimulants on Production of $\mathrm{O}_{2}^{-}$by Hemocytes Assayed Vla Stalning With NBT.

\begin{tabular}{ccc}
\hline Immunostimulants & Concentration & $\begin{array}{c}\text { Average Relative } \\
\text { Production of } \mathrm{O}_{2}^{-} \\
(n=15)\end{array}$ \\
\hline MCHBSS & - & $1.000 \pm 0$ \\
PMA & $250 \overline{\mathrm{ng} / \mathrm{mL}}$ & $1.296 \pm 0.249$ \\
Zymosan & $2.5 \mathrm{mg} / \mathrm{mL}$ & $2.014 \pm 0.276$ \\
B-glucan & $2.0 \mathrm{mg} / \mathrm{mL}$ & $2.525 \pm 0.504$ \\
\hline
\end{tabular}

Relative production of $\mathrm{O}_{2}^{-}=\mathrm{OD}_{630}$ of stimulated hemocytes $/ \mathrm{OD}_{630}$ of control hemocytes. 


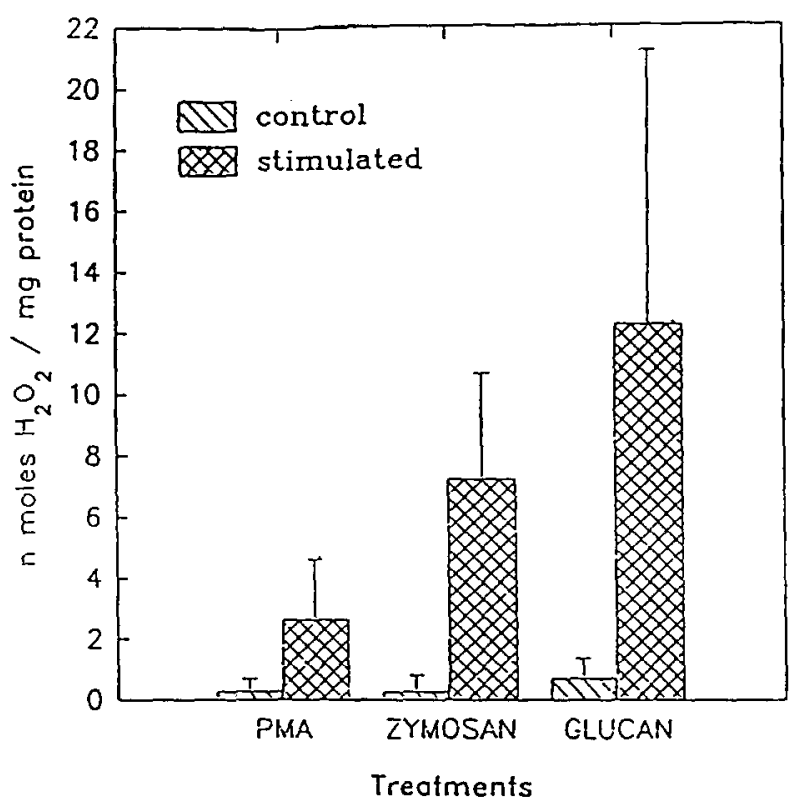

Flgure 2. Effects of different immunostimulants on the production of $\mathrm{H}_{2} \mathrm{O}_{2}$ by hemocytes assayed with oxidized phenol red. PMA: $250 \mathrm{ng} / \mathrm{mL}$; zymosan: $2.5 \mathrm{mg} / \mathrm{mL} ; \beta-g l u c a n: 2 \mathrm{mg} / \mathrm{mL}$. Sample sizes, PMA: 21; zymosan: 20; $\beta$-glucan: 23.

group); zymosan and $\beta$-glucan did not have any observable effects on this activity (Table 2).

\section{Discussion}

NBT staining was used to evaluate the effects of three immunostimulants, that is, for comparing both the amount of cytoplasmic blue granules and the percentage of hemocytes showing blue granules. Only $41 \%$ of $\beta$-glucan-treated hemocytes showed blue granules in their cytoplasm; more than half of the observed hemocytes remained inactive, showing that the adhesive hemocytes, mostly small granular cells, apparently did not undergo the respiratory burst. Hence, we believe that functionally different subpopulations probably exist among small granular hemocytes, showing the need for the further classification and separation of hemocytes.

Because $\mathrm{O}_{2}^{-}$is the first product released from a respiratory burst, $\mathrm{O}_{2}^{-}$measurement has been accepted as an accu- rate method for quantifying the intensity of a respiratory burst (1). A quantitative comparison of the stimulative effects of PMA and zymosan on shrimp hemocytes, as detected by the reduction of NBT, revealed that the amounts of intracellular $\mathrm{O}_{2}^{-}$produced by shrimp hemocytes were 1.3 and 2.0 times that of the control group, respectively. A similar result (1.2 times greater) was obtained from isolated rainbow trout macrophages that had been stimulated with PMA (15). However, the amounts of $\mathrm{O}_{2}^{-}$ released by human neutrophils were approximately 9 and 8 times normal levels following stimulation with either PMA or opsonized zymosan, respectively (16).

In addition, the stimulative effects of PMA and zymosan on shrimp hemocytes, as detected via the oxidation of phenol red, showed that amounts of released $\mathrm{H}_{2} \mathrm{O}_{2}$ were 17.9 and 25.8 times that of the control group, respectively. Meanwhile, the amount of $\mathrm{H}_{2} \mathrm{O}_{2}$ released by isolated rainbow trout macrophages treated with PMA was three times greater than normal (15). In addition, the 


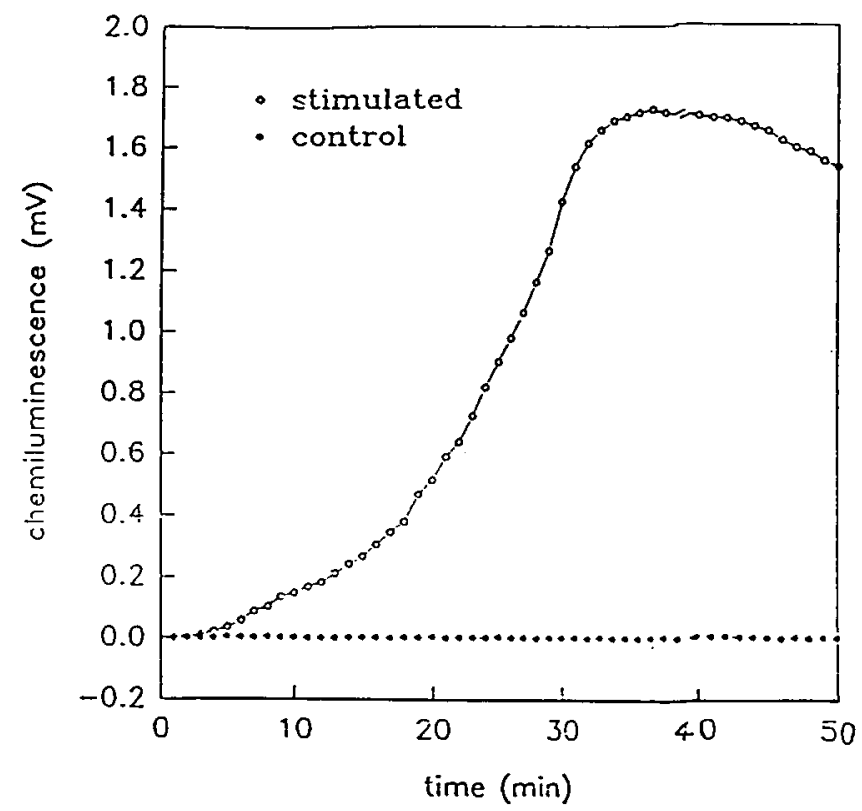

Figure 3. Chemiluminescence induced by $\mathrm{OCl}^{-}$anions produced by hemocytes treated with PMA $\left(500 \mathrm{ng} / \mathrm{mL}\right.$ ) at $24^{\circ} \mathrm{C}$. Hemocyte concentration: $5 \times 10^{7}$ cells $/ \mathrm{mL}$; luminol concentration: $0.1 \mathrm{mM}$.

amounts of $\mathrm{H}_{2} \mathrm{O}_{2}$ released by human macrophages following stimulation with PMA or opsonized zymosan were 120 and 23 times normal levels, respectively (17). Together, these results demonstrate that tiger shrimp responses to immunostimulants and the amounts of microbicidal substances generated by shrimp hemocytes were similar to those observed in fish macrophages, but generally lower than those observed in human monocytes and neutrophils.

One probable explanation for this difference is that the structure or number of receptors on the hemocyte membranes of shrimp, fish, and humans differ significantly. Oxygen metabolites released by phagocytes are highly reactive; it is possible that they play both beneficial and detrimental roles in chronic inflammation, and therefore the number of metabolites released by the phagocytes should be strictly regulated. As previously noted, luminol-enhanced chemiluminescence analysis showed that $\mathrm{OCl}^{-}$was not detectable in our observed stimulated shrimp hemocytes during the phagocytic process, probably because associated enzyme activity in the hemocytes was very low. Using $\mathrm{H}_{2} \mathrm{O}_{2}$ as a sub-

Table 2. Effects of Immunostimulants on Activity of Myeloperoxidase Extracted From Shrimp Hemocytes Assayed Vla Desser's Method.

\begin{tabular}{ccc}
\hline Immunostimulants & Concentration & $\begin{array}{c}\text { Average Relative } \\
\text { MPO Activity } \\
(n=10)\end{array}$ \\
\hline MCHBSS & - & $1.000 \pm 0$ \\
PMA & $500 \mathrm{ng} / \mathrm{mL}$ & $2.230 \pm 0.729$ \\
Zymosan & $2 \mathrm{mg} / \mathrm{mL}$ & $1.141 \pm 0.180$ \\
B-glucan & $2 \mathrm{mg} / \mathrm{mL}$ & $0.972 \pm 0.138$ \\
\hline
\end{tabular}

Relative MPO activity = MPO activity of stimulated hemocyes/MPO activity of control hemocytes. 
strate and guaiacol as an electron acceptor, we observed enzyme activity similar to that of human MPO; however, the enzyme activity of crude extract derived from broken hemocytes was much lower than that observed in human polymorphonuclear (PMN) leucocytes, probably because the shrimp MPO in our experiment was extracted from whole hemocytes instead of phagocytic cells (as in the case for studies involving human cells). The lack of detection of $\mathrm{OCl}^{-}$was further confirmed by the low rate of MPO enzyme activity observed in shrimp.

In conclusion, $\beta$-glucan had the strongest stimulative effect on hemocytes in terms of generating $\mathrm{O}_{2}^{-}$and $\mathrm{H}_{2} \mathrm{O}_{2}$, but PMA had the strongest stimulative effect on $\mathrm{OCl}^{-}$production and MPO activity, thus underscoring the fact that different immunostimulants affect different stages of the phagocytic process. Similar to microbicidal activity in human PMN, phagocytosis is correlated with the production of reactive oxygen species (18). It appears that $\mathrm{O}_{2}^{-}$and $\mathrm{H}_{2} \mathrm{O}_{2}$ play more important roles in tiger shrimp microbicidal activity when compared to $\mathrm{OCl}^{-}$and MPO activity; therefore, we suggest that treatment with $\beta$-glucan can enhance nonspecific disease resistance in shrimp. In addition, this nonspecific disease resistance may also account for previous observations of enhanced growth rates in tiger shrimp induced by treatment with $\beta$-glucan (19).

Acknowledgements - The authors are grateful to Dr. R. W. Lin for his many valuable suggestions and comments. They are thankful to Dr. D. P. Anderson for providing an original NBT staining protocol. Special thanks are also to Drs. H. Wakabayashi and $T$. Iida for providing an opportunity to learn the CL technique. This research was supported by the Council of Agriculture [Grant No. 80AD-7.1-F-121(62)] and the National Science Council (Grant No. 82-0211-B-002040), both of the Republic of China.

\section{References}

1. Secombes, C. J. Isolation of salmonid macrophages and analysis of their killing activity. In: Stolen, J. S.; Fletcher, T. C.; Anderson, D. P.; Roberson, B. S.; van Muiswinkel, W. B., Eds. Techniques in fish immunology. Fair Haven, NJ: SOS Publications, 1990:137-154.

2. Van Dyke, K.; Trush, M.; Wilson, J.; Stealey, P.; Miles, P. Luminol-dependent chemiluminescence analysis of cellular and humoral defects of phagocytosis using a chem-glo photometer. Microchem. J. 22:463-473; 1977.

3. Secombes, C. J.; Cheng, S.; Jeffries, A. H. Superoxide anion production by rainbow trout macrophages detected by the reduction of ferricytochrome C. Dev. Comp. Immunol. 12: 201-206; 1988.

4. Bell, K. L.; Smith, V. J. In vitro superoxide production by hyaline cells of the shore crab Carcinus maenas (L.). Dev. Comp. Immunol. 17:211-219; 1993.

5. Smith, V. J.; Soderhall, K. Beta-1,3-glucan activation of crustacean hemocytes in vitro and in vivo. Biol. Bull. 164:299-314; 1983.

6. Smith, V. J.; Soderhall, K.; Hamilton, M. Beta-1,3-glucan induced cellular defense reactions in the shore crab, Carcinus maenas. Comp. Biochem. Physiol. 77A:635-639; 1984.
7. Miosky, D. L.; Smolowitz, M.; Reinisch, C. L. Leukemia cell specific protein of the bivalve mollusc Mya arenaria. J. Invertebr. Pathol. 53:32-40; 1989.

8. Leslie, R. G. Q. Evaluation and improvement of a rapid microassay for measuring superoxide anion production by phagocytes: 1 . Spectrophotometric aspects. J. Immunol. Methods 103:253-259; 1987.

9. Leslie, R. G. Q.; Allen, R. Evaluation and improvement of a rapid microassay for measuring superoxide anion production by phagocytes: 2 . Biochemical aspects. J. Immunol. Methods 103:261-266; 1987.

10. Genfa, Z.; Dasgupta, P. K. Hematin as a peroxidase substitute in hydrogen peroxide determinations. Anal. Chem. 64:517-522; 1992.

11. Bakkenist, A. R. J.; Wever, R.; Vulsma, T.; Plat, H.; VanGelder, B. F. Isolation procedure and some properties of myeloperoxidase from human leucocytes. Biochim. Biophys. Acta. 524:45-54; 1978.

12. Pember, S. O.; Fuhrer-Krusi, S. M.; Barnes, K. C.; Kinkade, J. M. Isolation of three native forms of myeloperoxidase from human polymorphonuclear leukocytes. Fed. Eur. Biochem. Soc. Lett. 140:103-108; 1982.

13. Pember, S. O.; Shapira, R.; Kinkade, J. M. 
Multiple forms of myeloperoxidase from human neutrophilic granulocytes: Evidence for differences in compartmentalization, enzymatic activity, and subunit structure. Arch. Biochem. Biophys, 221:391-403; 1983.

14. Desser, R. K.; Himmelhoch, S. R.; Evans, W. H.; Januska, M.; Mage, M.; Shelton, E. Guinea pig heterophil and eosinophil peroxidase. Arch. Biochem. Biophys. 148:452-465; 1972.

15. Chung, S.; Secombes, C. J. Analysis of events occurring within teleost macrophages during the respiratory burst. Comp. Biochem. Physiol 89B:539-544; 1988.

16. Johnston, R. B. Jr.; Lehmeyer, J. E.; Guthrie,
L. A. Generation of superoxide anions and chemiluminescence by human monocytes during phagocytosis and on contact with surfacebound immunoglobulin G. J. Exp. Med. 143: 1551-1556; 1976.

17. Pick, E.; Keisari, Y. A. Simple colorimetric method for the measurement of hydrogen peroxide produced by cells in culture. J. Immunol. Methods 38:161-170; 1980 .

18. Segal, A. W. How do phagocytic cells kill bacteria? Med. Biol. 62:81-84; 1984.

19. Sung, H. H.; Kou, G. H.; Song, Y. L. Vibriosis resistance induced by glucan treatment in tiger shrimp (Penaeus monodon). Gyobyo Kenkyu 29:11-17; 1994. 